\title{
IDENTIFIKASI KONDISI POHON PENEDUH TERHADAP KESELAMATAN MANUSIA MENGGUNAKAN LOGIKA FUZZY MAMDANI
}

\author{
Indra Malik Akbar Fadhilah \\ Program Studi Teknik Informatika Fakultas Industri Kreatif dan Telematika Universitas Trilogi \\ Jln.TMP Kalibata no.1 - Jakarta Selatan \\ indramaikakbar135@gmail.com
}

\begin{abstract}
Abstrak - Kondisi pohon peneduh merupakan suatu hal yang sangat penting untuk keselamatan para pengguna jalan. Kerap terjadi tumbangnya pohon peneduh dikarenakan faktor-faktor suhu, iklim, polusi udara, dan kurangnya oksigen pada pepohonan. Tujuan dari penelitian ini adalah untuk mengetahui kondisi kesehatan pada pohon peneduh terhadap keselamatan manusia. Maka untuk menyelesaikan permasalahan pada penelitian ini akan dibuatnya program tebang pilih pada pohon peneduh dengan menerapkan metode logika fuzzy untuk memecahkan permasalahan dari faktor-faktor yang ada dengan membuat variable-variable yang akan digunakan dalam pemporsesan pada logika fuzzy. Hasil dari penelitian ini ialah untuk mengidentifikasi kondisi kesehatan pada pepohonan mana saja yang sudah layak untuk dilakukan penebangan sesuai hasil dari logika fuzzy.
\end{abstract}

Kata kunci- Identifikasi, Pohon Peneduh, Keselamatan Manusia, Fuzzy Mamdani.

\section{Pendahuluan}

Pada umumnya kecelakaan terjadi karna dua faktor yaitu alam dan manusia. Faktor alam bisa terjadi seperti tumbangnya pohon yang menyebabkan terancamnya keselamatan seseorang yang beraktifitas pada sekitaran pepohonan. Sedangkan faktor manusia bisa terjadi seperti sengaja melanggar suatu aturan yang sudah ditetapkan sehingga bisa terjadinya kecelakaan. Dilihat dari data BPBD Jakarta 248 pohon tumbang yang terjadinya ditahun 2018 tidak ada korban jiwa akan tetapi ada beberapa sarana yang rusak.

Memperhatikan hal tersebut keselamatan merupakan kondisi dimana suatu keadaan atau tempat yang benar-benar aman dari segala ancaman yang kerap kali mengancam keselamatan. Keselamatan merupakan suatu kondisi yang paling diutamakan dalam berbagai aktifitas baik itu dalam pekerjaan, berkendara, dan berlibur sekalipun. Dengan itu keselamatan seseorang ketika beraktifitas melewati pepohonan peneduh sangat diutamakan, karena dari kecelakaan tumbangnya pohon tersebut tidak ada yang bisa dipertanggung jawabkan jika seseorang terkena runtuhan pohon tersebut.
Penyebab tumbangnya pepohonan disebakan oleh dua faktor, yaitu manusia dan lingkungan. Faktor manusia biasanya manusia sering melakukan vandalism, seperti memaku poster dipepohonan, sengaja membuat sempal pada pepohonan yang mengakibatkan pepohonan rusak karena ulah manusia yang seperti itu. Sedangkan faktor lingkungan bisa terjadi karena suhu, iklim, kelembaban, polusi udara dan kurangnya oksigen pada pepohonan peneduh yang menyebabkan rusaknya pepohonan tersebut.

Logika fuzzy merupakan logika yang samar dimana suatu logika yang cocok untuk diimplementasikan untuk system control pemecahan masalah. Maka dari penelitian ini menggunakan metode logika fuzzy untuk mengidentifikasi kondisi pada pepohonan dengan faktor-faktor tersebut yang nantinya akan dilakukan pembuatan variable-variable untuk memudahkan dalalm pemprosesan pada logika fuzzy.

Permasalahan diatas dapat diatasi dengan pembuatan program kerja tebang pilih pada pohon peneduh merupakan jawaban atau solusi dari penulis terhadap tumbangnya pepohonan peneduh yang ada disekitar lingkungan atau di jalan-jalan raya. Maka hasil dari identifikasi menggunakan fuzzy mamdani sangat berguna untuk menentukan pepohonan mana yang sudah layak untuk ditebang sehingga dapat 
meminimalisir tumbangnya pepohonan terkhusus pohon peneduh. Pada penelitian ini diharapkan dapat membantu masyarakat untuk mengaja kondisi pohon peneduh yang berada di jalan-jalan raya ataupun disekitar lingkungannya.

\section{Metodologi Penelitian}

\section{A. Definisi Logika Fuzzy}

Dalam penelitian ini penulis menggunakan metode logika fuzzy. Definisi logika fuzzy adalah berperan sebagai drajat keanggotaan dan penentu dalam penentuan suatu himpunan. Pada logika fuzzy terdapat nilai keanggotaan yang sangat penting dalam logika fuzzy karena untuk dijadikan penalaran dalam sebuah kasus permasalahan[1]. Penulis mempunyai alasan kenapa memilih metode logika fuzzy, karena langkahlangkah penyelesaiannya cocok untuk memecahkan atau menentukan suatu permasalahan yang terdapat pada obyek penelitian ini. Selain itu, logika fuzzy merupakan sebuah logika samar dan mempunyai dua nilai penting diantaranya true dan false, logika fuzzy juga memiliki operator dan tahaptahapan untuk menyelesaikan masalah diantaranya fuzzyfication, Inference, dan defuzzyfication.

\section{B. Flowchart Metode}

Flowchart metode merupakan suatu alur dari penelitian yang penulis bahas yaitu Identifikasi Kondisi Pohon Peneduh Terhadap Keselamatan Manusia Menggunakan Logika Fuzzy dengan menggunakan metode dari Mamdani, dimana tahapan awal pengumpulan data untuk variable-variable yang nantinya perhitungan fuzzy akan dimasukkan kedalam MATLAB untuk dilakukannya proses pengujian dari variable-variable input dan rules yang telah kita masukkan ke MATLAB maka akan menghasilkan suatu perhitungan yang menggambarkan hasil tersebut sesuai dengan permasalahan pada penelitian ini atau tidak.

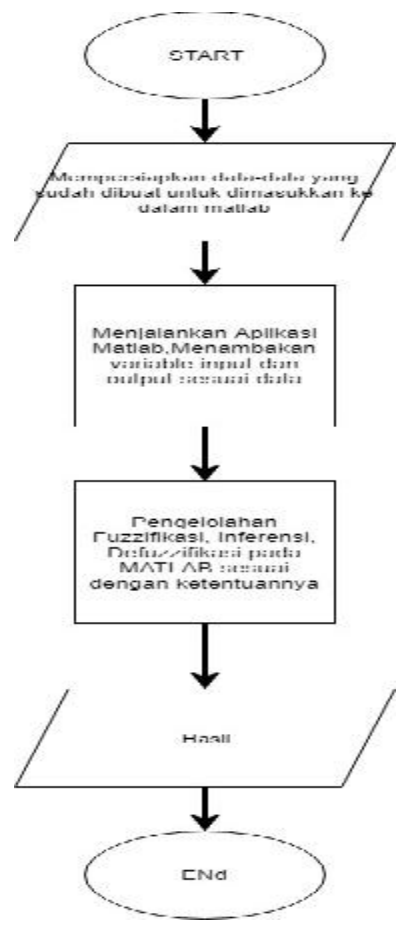

Gambar. 1 Flowchart

\section{Pengumpulan Data}

Pengumpulan data ini bermaksud untuk mempersiapkan kebutuhan dari logika fuzzy yang akan digunakan diantarnya variable-variable input atau output. Dengan adanya pengumpulan data ini besar/satuan yang besaran/satuan yang digunakan lebih jelas dan meminimalisir terjadinya kesalahan disaat perhitungan.

Tabel 1

Tabel data

\begin{tabular}{|c|c|c|}
\hline Variabel & Nilai Min & Nilai Max \\
\hline Kerusakan & $0 \%$ & $100 \%$ \\
\hline Usia & 0 thn & 50 thn \\
\hline Jarak Antar Pohon & $0 \mathrm{~m}$ & $5 \mathrm{~m}$ \\
\hline Kondisi Kesehatan & $0 \%$ & $100 \%$ \\
\hline
\end{tabular}

Dari table diatas menunujukkan nilai terendah dan tertinggi dari kerusakan pada pohon, usia pohon, jarak antar pohon yang ada pada saat ini dan data pada table diatas akan digunakan menjadi variable input dan output. Selain itu agar terlihat lebih jelas maka akan dijelaskan pada table selanjutnya.

Tabel 2

Tabel variabel dan semesta

\begin{tabular}{|l|l|c|}
\hline \multirow{2}{*}{ Jenis } & \multicolumn{1}{|c|}{ Nama } & Pembicaraan Semesta \\
\hline \multirow{3}{*}{ Input } & Kerusakan & {$[0-60-100]$} \\
\cline { 2 - 3 } & Usia & {$[0-30-50]$} \\
\cline { 2 - 3 } & Jarak Antar Pohon & {$[0-3-5]$} \\
\hline Output & Kondisi Kesehatan & {$[0-60-100]$} \\
\hline
\end{tabular}

Tabel diatas merupakan satu langkah untuk menentukan setiap nama variable input dan output dan termasuk menentukan keseluruhan range pada variable input atapun output dalam himpunan semesta. Selanutjnya daftar table seluruh himpunan lengkap dengan nama himpunan perdomain dan per variable juga.

Tabel 3

Tabel variabel dan himpunan

\begin{tabular}{|c|c|c|c|c|}
\hline Jenis & Variabel & Himpunan & $\begin{array}{c}\text { Pembicaraan } \\
\text { Semesta }\end{array}$ & Domain \\
\hline \multirow[t]{3}{*}{ Input } & Kerusakan & $\begin{array}{l}\text { Kerusakan } \\
\text { Ringan, } \\
\text { Kerusakan } \\
\text { Ringan, } \\
\text { Kerusakan } \\
\text { Berat) }\end{array}$ & {$[0-100]$} & $\begin{array}{l}{[0-60,50-} \\
80,70-100]\end{array}$ \\
\hline & Usia & $\begin{array}{l}\text { (Muda, Cukup, } \\
\text { Tua) }\end{array}$ & {$[0-50]$} & $\begin{array}{l}{[0-30,25-} \\
40,35-50]\end{array}$ \\
\hline & $\begin{array}{l}\text { Jarak Antar } \\
\text { Pohon }\end{array}$ & $\begin{array}{c}\text { (Dekat, Sedang, } \\
\text { Jauh) }\end{array}$ & {$[0-5]$} & $\begin{array}{c}{[0-3,2-4,} \\
3-5]\end{array}$ \\
\hline
\end{tabular}




\begin{tabular}{|l|l|c|c|c|}
\hline Output & Kondisi & (Gejala, Sakit, & {$[0-100]$} & {$[0-50,40-$} \\
& Kesehatan & Sehat $)$ & & $80,60-100]$ \\
\hline
\end{tabular}

\section{Pengelolaan Data pada MATLAB}

Pada tahap ini menjelaskan tentang pengelolahan data yang telah dipaparkan dari tabel yang berada diatas dan akan dipaparkan lebih rinci dalam Bab III Hasil dan Pembahasan.

\section{HASIL DAN PEMBAHASAN}

Fuzifikasi

Pada tahapan fuzzifikasi ini merupakan tahapan penginputan nilai-nilai yang sudah dibuat ke dalam MATLAB dengan ketentuan logika fuzzy dimana range nya dari 0 sampai 1.

1. Pertama membuka MATLAB akan muncul tampilan seperti ini

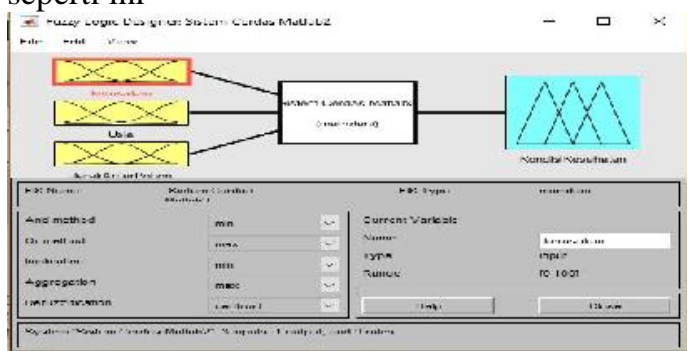

Gambar.2 Tampilan Awal MATLAB

Pada tampilan awal untuk fungsi fuzzy di MATLAB akan tampil seperti tampilan yang ada di gambar di atas, dimana pada sewaktu masuk awalan terdapat kotak bewarna kuning satu itu untuk variabel input, yang bewarna putih untuk rules pada fuzzy di MATLAB sedangkan kotak yang bewarna biru untuk variabel output. Pada awalan masuk di fungsi fuzzy pada MATLAB hanya terdapat satu inputan, satu output. Jadi sesuaikan dulu dengan data yang mau dihitung.

1. Tahap pertama, membuat fungsi keanggotaan diantaranya :

\section{Variabel Input}

a. Kerusakan

Kerusakan dari pepohonan dijadikan salah satu variabel inputan yang dimana mempunyai skala kerusakan dengan per\% sebagai tolak ukur kerusakan pada pepohonan tersebut. Pada fungsi MATLAB kurva yang digunakan pada variabel input kerusakan ialah kurva segitiga dan kurva trapesium. Nilai atau range dari kerusakan pepohonan ini sangat berpengaruh ke variabel input lainnya jadi harus benar-benar detail agar meminimalisir kesalahan dalam melakukan pemprosesan bahkan hasilnya tersebut.

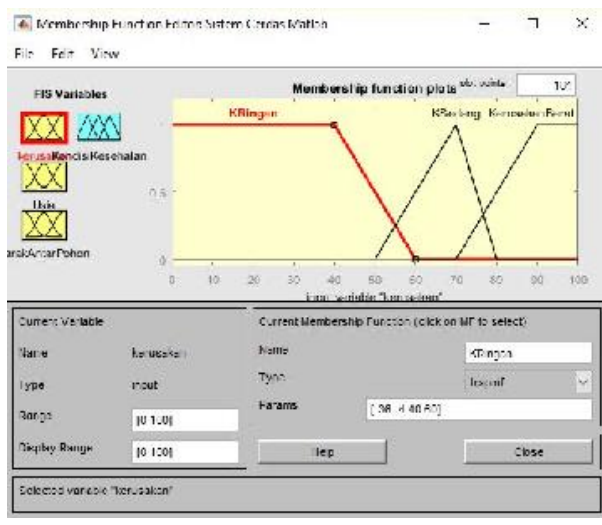

Gambar.3 Keanggotaan Kerusakan

\section{b. Usia}

Pada variabel input fungsi keanggotaan dari usia sama seperti fungsi keanggotaan yang sebelumnya, sangat berpengaruh untuk pemprosesan ataupun hasil nanti. Kurva yang digunakan pada variabel input usia ini menggunakan trapesium dan segitiga.

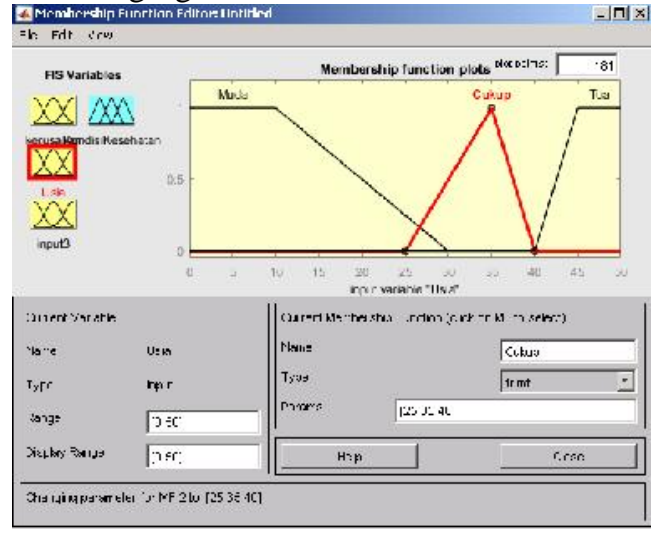

Gambar.4 Keanggotaan Pada Variabel Input Usia

c. Jarak Antar Pohon

Jarak antar pohon sangat berpengaruh dalam menentukan output dari kondisi kesehatan pada pohon tersebut, dan seperti yang sebelumnya penggunaan kurva tidak jauh.

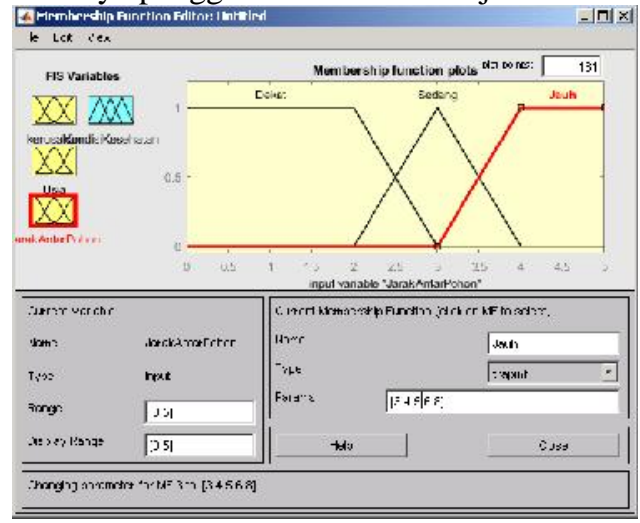


Gambar.5 Keanggotaan Pada Variabel Input Jarak Antar Pohon

\section{Variabel Output}

d. Kondisi Kesehatan

Kondisi kesehatan ini merupakan variabel output yang mencakup dari hasil pengolahan variabel-variabel input lainnya yang akan dikelola pada fungsi inferensi yang selanjutnya akan dibuat.

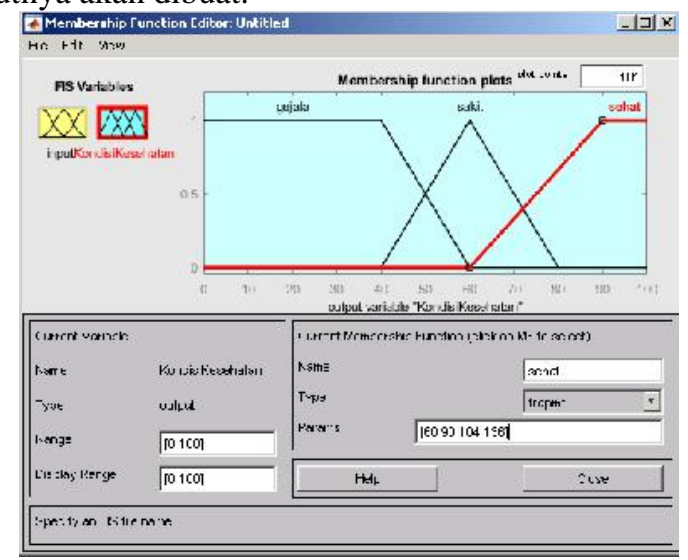

Gambar.6 Keanggotaan Pada Variabel Output Jarak Antar

Pohon

Pada pembuatan fungsi keanggotaan diatas semua kurva itu ialah kurva linear yang berguna untuk nilai himpunan paling rendah, dan paling tinggi sedangkan untuk nilai himpunan yang standar atau menengah menggunakan kurva linear segitiga. Tujuan dari pembuatan kurva tersebut untuk meminimalisir kesalahan dari nilai-nilai himpunan jika nilai himpunan sudah mulai memasuki nilai tertinggi.

\section{Inferensi}

2. Pembuatan aturan-aturan yang merupakan kebutuhan dari logika fuzzy untuk melakukan pengolahan pada setiap varibel input menjadi output.

Inferensi adalah tahapan menentukan aturan atau rules dari logika fuzzy dari variabel input dan output yang nantinya akan menampung nilai-nilai sebagai acuan untuk penalaran dalam rules logika fuzzy.

Pembuatan rules pada tahapan inferensi ini sangat mempengaruhi hasil output nya nanti dan dimasukkan dengan operator-operator logika matematika seperti OR, NOT, atau AND sehingga membuat hasil nilai benar-benar kecil, adapun contoh rules:

- If Kerusakan Ringan AND Usia Muda AND Jarak Antar Pohon Dekat Then Kondisi Kesehatan adalah Sehat

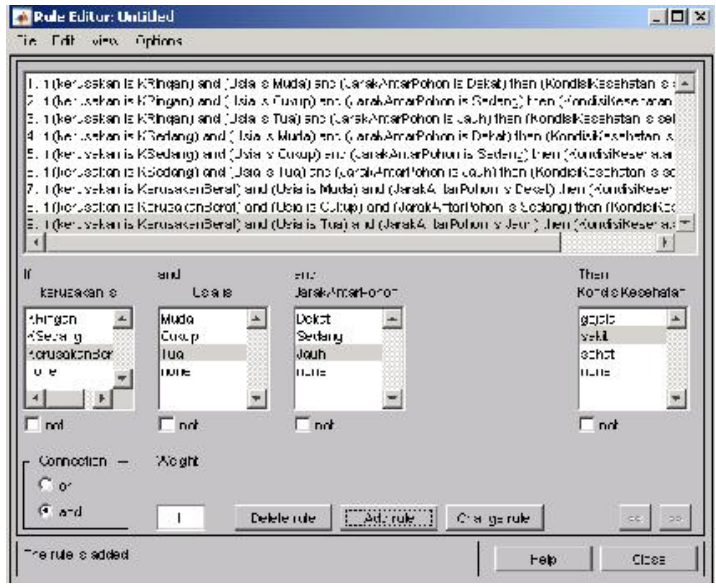

Gambar.6 Rules pada MATLAB

\section{Defuzzifikasi}

3. Tahapan ini penulis menampilkan hasil nilai dari softwawre MATLAB dalam melakukan pengujian

Ti FueV Vener: risten Cerdas Motsto

Hic =cit Vice Uotions
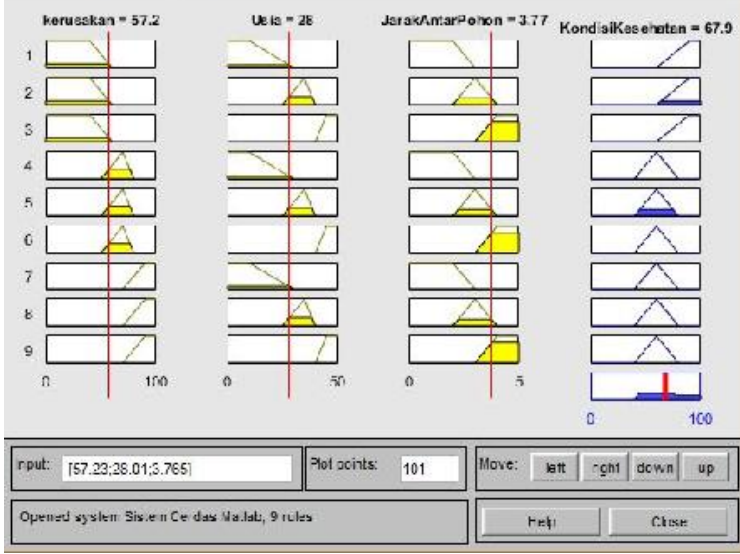

Gambar.7 Bagian Rules View pada MATLAB

4. Ruls Vewcr: Sistem Ecrdas Matlab

Fil E Edt Vow Optiors
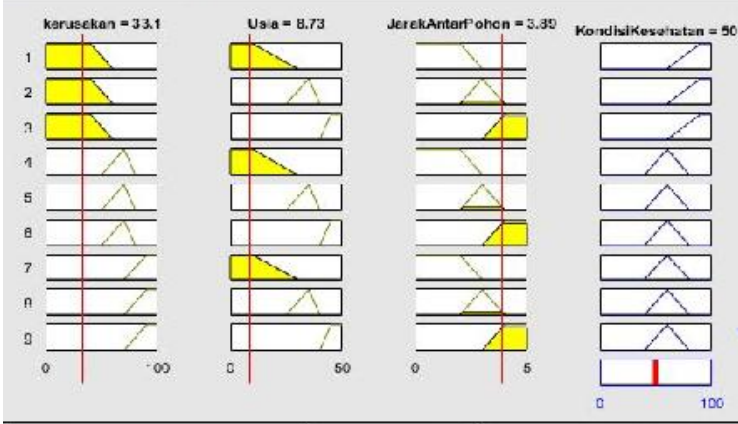

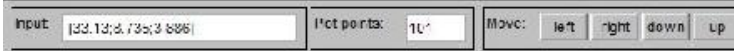

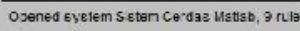


Gambar.8 Bagian Rules View pada MATLAB

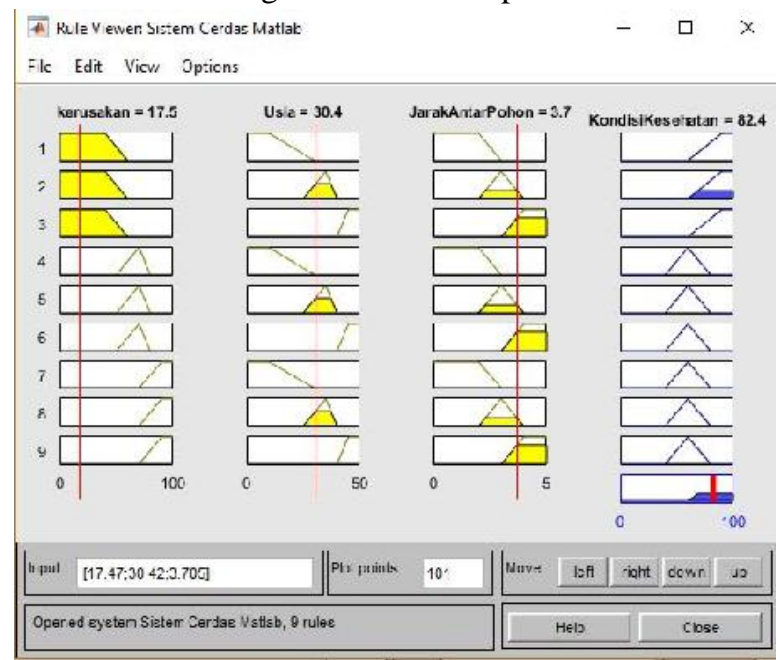

Gambar.8 Bagian Rules View pada MATLAB

Gambar diatas menjelaskan bahwa pada software MATLAB dapat melakukan percobaan dengan merubah-rubah nilai input sesuai dari variable input akan tetapi ini bebas dalam melakukan percobaan sehingga dapat menghasilkan hasil yang berbeda-beda dan nilai masukkan yang berasal dari nilai real akan dikeluarkan dan ditampilkan lagi/defuzzifikasi.

\section{KESIMPULAN}

Kesimpulan pada identifikasi pohon peneduh terhadap keselamatan manusia dengan menggunakan metode logika fuzzy mamdani bahwa metode logika fuzzy adalah metode yang cocok untuk dilakukan pengembangan lebih lanjut dalam permasalahan pembuatan aplikasi dan penerapannya. Dengan adanya penelitian ini penulis mengharapkan masyarakat sadar akan kesehatan kondisi pohon-pohon yang dijadikan sebagai pohon peneduh. Penulis berharap dengan adanya penelitian ini dapat dipakai atau diterapkan untuk melakukan program kerja tebah pilih pohon peneduh.

\section{REFERENSI}

[1] Noviady, I. (2015). Identifikasi kondisi kesehatan pohon peneduh di kawasan Ecopark, Cibinong Science Center. Pros Sem Nas Masy Biodiv Indon, 1(September), 13851391. https://doi.org/10.13057/psnmbi/m010621

[2] Pitopang, R. (2017). Inventarisasi Jenis Dan Tingkat Kesehatan Pohon Pelindung Di Kota Palu, Sulawesi Tengah. Jurnal Manajemen Hutan Tropika V,11 no 1, 43.
[3] Sriwijaya, J., Majapahit, J., Sudarso, J. Y., Langko, J., \& Mataram, K. (2013). Morfologi spesies tanaman peneduh jalan di kota mataram. Retrieved from http://eprints.unram.ac.id/4726/1/Wayan Arya Purnawijaya \%28e1a009001\%29.Pdf

[4] Tukiran, J. M., Ariffin, J., \& Ghani, A. N. A. (2016). Cooling effects of two types of tree canopy shape in Penang, Malaysia. International Journal of GEOMATE.

[5] Wibowo, S. (2015). Penerapan Logika Fuzzy Dalam Penjadwalan Waktu Kuliah. Informatika UPGRIS, 1(Juni), 59-77. https://doi.org/http://dx.doi.org/10.26877/jiu.v1i1\%2 0Juni.809

[6] Widaningrum, I. (2015). Analisis Hubungan Proses Pembelajaran dengan Kepuasan Mahasiswa Menggunakan Logika Fuzzy. Scientific Journal of Informatics, 2(1), 91-98.

[7] Zayadi, H., \& Hayati, A. (2017). Distribusi spasial pohon peneduh jalan raya Lowokwaru Kota Malang dengan aplikasi GIS. Jurnal Ilmiah BIOSAINTROPIS (BIOSCIENCE-TROPIC, 3, 46-52. Retrieved from http://biosaintropis.unisma.ac.id/index.php/biosaintro pis/article/view/103/52 